\title{
Radiological correlation with functional outcome in displaced proximal humerus fractures treated with locking plates: a prospective study of 35 cases
}

\author{
Neetin Pralhad Mahajan, Nikhil Dilip Palange*, Eknath D. Pawar, \\ Hitesh Jivrajbhai Mangukiya, Ujwal Suryabhan Ramteke, Vedashish Ravesh, \\ Umesh Jadhav, Prasannakumar G. S.
}

Department of Orthopaedics and Traumatology, Grant Government Medical College, Mumbai, Maharashtra, India

Received: 01 January 2018

Revised: 26 February 2018

Accepted: 28 February 2018

\section{*Correspondence:}

Dr. Nikhil Dilip Palange,

E-mail: npalange@gmail.com

Copyright: () the author(s), publisher and licensee Medip Academy. This is an open-access article distributed under the terms of the Creative Commons Attribution Non-Commercial License, which permits unrestricted non-commercial use, distribution, and reproduction in any medium, provided the original work is properly cited.

\begin{abstract}
Background: The objective of this prospective study is to investigate the relationship between the functional outcome and the radiographic results of two-, three- and four part proximal humeral fractures treated with open reduction and fixation with PHILOS locking plate.

Methods: 35 patients (30 males and 5 females) with displaced proximal humerus fracture were treated with PHILOS plating and studied prospectively. According to Neer's classification there were 16 two part fracture (45\%), 15 three part fracture (42\%) and 4 four part fracture (13\%). The healing of fracture, head shaft angle (HSA) and complications were evaluated radiologically with plain radiographs whereas the functional outcome was assessed by the Shoulder Pain and Disability Index (SPADI) at 6 weeks, 3 months, 6 months and 1 year after surgery.

Results: In our study, patients treated with locking plates had mean forward flexion of $123^{\circ}$, abduction of $124^{\circ}$, mean external rotation of $30^{\circ}$ and internal rotation $53^{\circ}$ at 1 year follow-up. Maximum improvement in range of movement occurred between interval of 12 weeks to 24 weeks due to complete fracture union occurred approximately up to 12 weeks. The mean SPADI score at end of 1 year were 10.22, 10.38 and 10.20 for two, three and four part fractures respectively. Average postoperative and follow-up HSA's were 134.1 \pm 4.4 and $132.5 \pm 1.2$ degrees, respectively. Varus progression was more prominent in patients with postoperative HSA $<130(\mathrm{p}<0.001)$. Complications included impingement in 1 case, joint penetration by screw in 1 case, failure of fixation in 1 case and infection in 1 case.

Conclusions: Fixed angle locked plate is an extremely useful implant for reconstruction and salvage of proximal humeral fractures. Precise surgical technique, stable fracture fixation and restoration of anatomical reduction are absolutely necessary for improved outcome.
\end{abstract}

Keywords: Displaced, Proximal humerus, Clinical, Radiological, Correlation

\section{INTRODUCTION}

Proximal humerus fractures account for $4-5 \%$ of all fractures. ${ }^{1}$ Old age and osteoporosis are the most important risk factors for these fractures. In such patients, even low energy trauma like a fall can lead to fracture as compared to younger age group with adequate bone stock, in whom a high energy trauma like road traffic accident is associated cause of fracture. Conservative treatment is reserved for undisplaced fractures. Various 
modalities like percutaneous pinning, intra medullary nail, transosseous sutures, locking plate fixation and arthroplasty have been advocated for tratment of displaced proximal humerus fractures, which make up about $15-20 \%$ of the proximal humeral fractures., ${ }^{2,3}$ According to Neer, displacement is defined as more than $1 \mathrm{~cm}$ of translation or more than 45 degrees of angulation between the fragments. ${ }^{4} \mathrm{He}$ classified these fractures according to the number of fragments, as two, three and four part fractures. Of all the fixation modali ties available, the locking plate has been shown to be the most effective, although no fixation method is completely ideal. The introduction of the fixed angle locking plate has further enabled anatomical reduction and fixation. Anatomical reduction is essential for restoration of biomechanical relationship of the shoulder joint and hence good function of the upper limb. ${ }^{5}$

Traditionally, the deltopectoral approach has been used to approach proximal humeral fractures. This approach is simple, extensile and has less risk of injury to the axillary nerve than the deltoid splitting approach. However, it has disadvantages like extensive soft tissue stripping and longer scar formation. Gardner introduced he anterolateral deltoid splitting approach which has been used in MIPPO technique. ${ }^{6}$ It is associated with less soft tissue stripping, preservation of blood supply to the humeral head and direct visualisation of the greater tuberosity.

The present study aims to evaluate the correlation of the radiological as functional outcome of displaced proximal humeral fractures treated with locked plate (PHILOS).

\section{METHODS}

A prospective study of 35 consecutive patients with displaced proximal humerus fractures was carried out in our institution from May 2014 to October 2016. After getting permission from the ethical committee and taking written valid informed consent, patients aged 20 to 60 years with closed two, three and four part fractures of the proximal humerus operated with PHILOS plate fixation within 3 weeks of injury, were included in the study. Patients with open fractures, pathological fractures, associated neurovascular injuries and injury to ipsilateral elbow or distal humerus were excluded from the study. Similarly, patients with past history of surgery in ipsilateral shoulder, and polytrauma were excluded. All patients were subjected to meticulous clinical examination to rule out neurovascular injury and trauma to other limbs. Radiological evaluation in form of radiograph of the shoulder and fine cut sagittal and coronal CT were done to evaluate the number of fragments and their displacement to aid in fracture classification and intra-operative fracture reduction. All fractures were classified by system proposed by Neer. ${ }^{4}$

All patients were preoperatively evaluated to rule out any local or systemic foci of infection, diabetes, cardiac problems which may subsequently cause shoulder stiffness and restricted shoulder movement.

The patients with radiological evidence of osteoporosis were stared on therapy with calcium, vitamin D and injection zolendronic acid.

\section{Surgical technique}

The patient was positioned supine in "Beach chair position" on a radioluscent operating table. After scrubbing, painting and draping (leaving the arm free) under aseptic precautions, the fracture was approached via the standard delto-pectoral approach. The skin incision was marked between the tip of coracoid process and the deltoid tuberosity. After taking incision through skin and subcutaneous tissue, the cephalic vein is identified. This vein runs along the delto-pectoral interval, which is the inter-nervous plane between the deltoid (axillary nerve) and the pectoralis major (medial and lateral pectoral nerve). The cephalic vein was retracted medially and ligated if required. After incising the clavi-pectoral fascia, the conjoined tendon was retracted medially. Further exposure was obtained by limted release of the insertion of deltoid fibres on the deltoid tuberosity. The long head of biceps in the bicipital groove was identified and protected as it helps in orientation in comminuted fractures. Care was taken to avoid excessive disruption of soft tissues through bicipital groove so as to preserve the ascending branch of the anterior circumflex humeral artery. This branch is located laterally in the groove and is primary blood supply to the head fragment.

After freshening the fractured surfaces, temporary reduction was achieved with $\mathrm{k}$ wires. Stay sutures were placed in rotator cuff. Tuberosity fractures were held with non-absorbable sutures to allow control of the fragments and achieve reduction. After confirming reduction, the precontoured locking plate was positioned 5-10 $\mathrm{mm}$ lateral to the intertubercular sulcus and $10 \mathrm{~mm}$ distal to tip of greater tuberosity. The plate was fixed first with a cortical screw to hold the plate. Proximal locking screws were extended upto the subchondral bone. Bicortical locking screws were placed into the humeral shaft. The inferomedial locking screw to prevent varus collapse was inserted in most cases, of screws and to rule out intraarticular penetration of the proximal screws. After confirming reduction, adequate fixation and range of motion, the wound was closed in layers under a drain.

Post operatively, the arm was immobilised in a sling. Check dressing of the sutures was done on $2^{\text {nd }}$ postoperative day and drain was removed. Sutures were removed on day 10 to $14^{\text {th }}$. Mobilisation exercises were started from the $2^{\text {nd }}$ post- operative day. Gentle abduction upto 60 degrees and pendulum exercises with no forced external rotation upto 6 weeks was allowed. Full ROM was started after 6 weeks. Patients were followed up on outpatient basis at 6 weeks, 3 months, 6 months and 1 
year after surgery. On each visit, patients were evaluated clinically and radiologically. Standard antero-posterior and lateral radiographs were taken to note the status of fracture healing, plate position, implant related complications, anatomical alignment (major varus or valgus), and post-operative osteonecrosis of the humeral head.

\section{Functional evaluation}

All patients were evaluated using the shoulder pain and disability index (SPADI). ${ }^{7}$

\section{Interpretation of scores}

Total pain score: $/ 50 \times 100=\%$
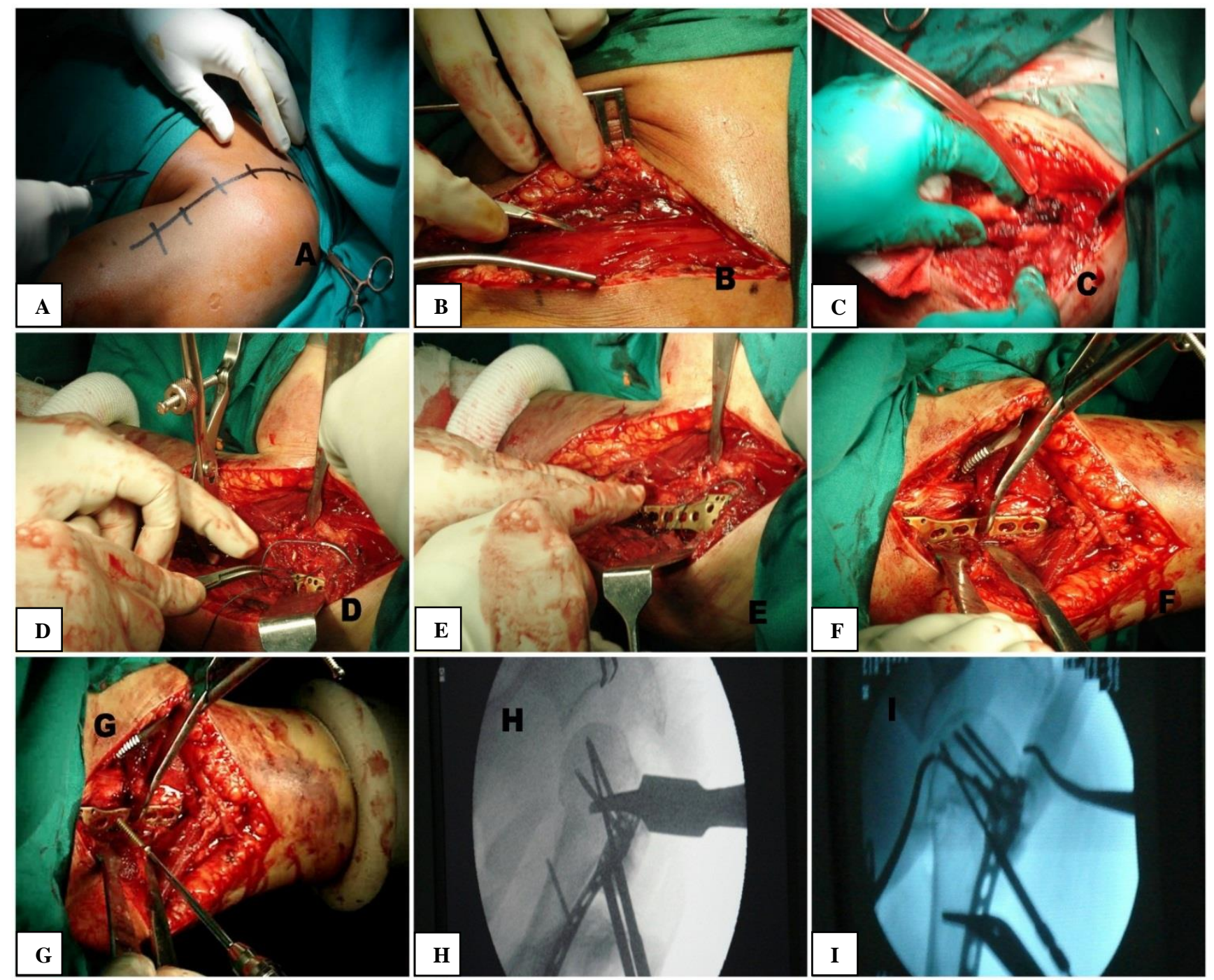

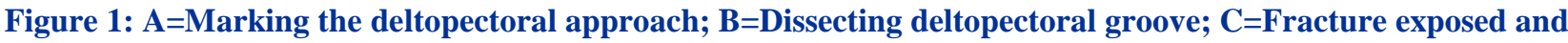
biceps tendon identified; $D=$ Sutures through rotator cuff; $E=$ Rotator cuff sutures passed through the plate;

$F=$ Locking plate held to shaft with reduction forceps; $G=$ Plate first fixed to distal fragment with a cortical screw; $\mathrm{H}=$ Passing proximal locked head screws under $\mathrm{C}$-arm guidance; I=Confirming the position of inferomedial locking screw. 
Table 1: Shoulder pain and disability index (SPADI).

\begin{tabular}{|llllllllllll|}
\hline Pain scale- how severe is your pain? & \multicolumn{1}{ll|}{} \\
\hline At its worst? & 0 & 1 & 2 & 3 & 4 & 5 & 6 & 7 & 8 & 9 & 10 \\
\hline When lying on the involved side? & 0 & 1 & 2 & 3 & 4 & 5 & 6 & 7 & 8 & 9 & 10 \\
\hline Reaching for something on a high shelf? & 0 & 1 & 2 & 3 & 4 & 5 & 6 & 7 & 8 & 9 & 10 \\
\hline Touching the back of your neck? & 0 & 1 & 2 & 3 & 4 & 5 & 6 & 7 & 8 & 9 & 10 \\
\hline Pushing with the involved arm? & 0 & 1 & 2 & 3 & 4 & 5 & 6 & 7 & 8 & 9 & 10 \\
\hline Disability scale- how much difficulty do you have? & & & & & & & & & \\
\hline Washing your hair? & 0 & 1 & 2 & 3 & 4 & 5 & 6 & 7 & 8 & 9 & 10 \\
\hline Washing your back? & 0 & 1 & 2 & 3 & 4 & 5 & 6 & 7 & 8 & 9 & 10 \\
\hline Putting on an undershirt or jumper? & 0 & 1 & 2 & 3 & 4 & 5 & 6 & 7 & 8 & 9 & 10 \\
\hline Putting on a shirt that buttons down the front? & 0 & 1 & 2 & 3 & 4 & 5 & 6 & 7 & 8 & 9 & 10 \\
\hline Putting on your pants? & 0 & 1 & 2 & 3 & 4 & 5 & 6 & 7 & 8 & 9 & 10 \\
\hline Placing an object on a high shelf? & 0 & 1 & 2 & 3 & 4 & 5 & 6 & 7 & 8 & 9 & 10 \\
\hline Carrying a heavy object of 10 pounds (4.5 kilograms) & 0 & 1 & 2 & 3 & 4 & 5 & 6 & 7 & 8 & 9 & 10 \\
\hline Removing something from your back pocket? & 0 & 1 & 2 & 3 & 4 & 5 & 6 & 7 & 8 & 9 & 10 \\
\hline
\end{tabular}

\section{Radiological evaluation}

Radiological evaluation was done with noting the healing of fracture, head shaft angle (HSA) and complications.

\section{Healing}

On consecutive radiographs on follow-ups, the fracture was assessed for healing by assessing callus formation. Fracture was considered to be healed when there was evidence of callus on at least 3 cortices on AP and lateral radiographs.

\section{Head-shaft angle (HSA)}

The HSA was calculated based on the method described by Hertel et al. ${ }^{8}$

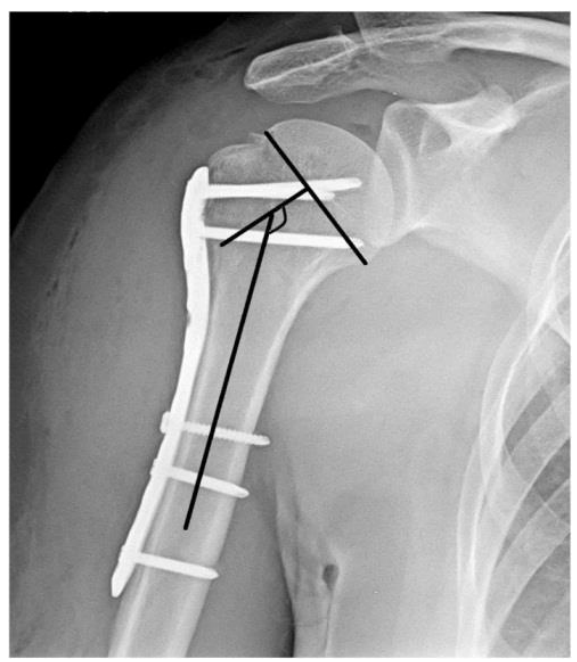

Figure 2: HSA is measured by the angle made by axis of humeral shaft intersecting with the perpendicular to the line joining the tuberculum majus and the inferior most part of the articular surface of the humeral head.
All data was analysed with the SSSP software. Comparison of postoperative and follow-up HSA measurements, comparison of varus progression between patients with primary reduction less and more than 130 degrees, and between patients with or without IMCS and varus progression, in terms of fracture type and age, were analyzed with analysis of variance for repeated measures. Comparison of functional outcomes of patients with or without varus progression, in terms of fracture type and age, were analyzed with Student's t-test; $p$ values less than 0.05 were considered statistically significant.

\section{RESULTS}

In our study, there were a total of 35 patients, out of which 30 were males and 5 females which suggests higher male preponderance. All patients were in the age group from 2 nd to the sixth decade with the average age being 44 yrs. Among these, 55\% patients are from 5th and 6th decade of life (Table 2).

Table 2: Age distribution of fracture.

\begin{tabular}{|lll|}
\hline Age group (years) & $\begin{array}{l}\text { Number of } \\
\text { patient }\end{array}$ & $\begin{array}{l}\text { Percentage } \\
(\%)\end{array}$ \\
\hline 21 to 30 & 9 & 25 \\
\hline 31 to 40 & 7 & 20 \\
\hline $\mathbf{4 1}$ to 50 & 7 & 20 \\
\hline $\mathbf{5 1}$ to 60 & 12 & 35 \\
\hline Total patients & 35 & \\
\hline
\end{tabular}

According to Neer's classification there were 16 two part fracture $(45 \%), 15$ three part fracture $(42 \%)$ and 4 four part fracture (13\%) (Table 3$){ }^{4}$

$54 \%$ patients had fracture of the left proximal humerus. Non dominant side was involved in $53 \%$ of patient. 
Table 3: According to NEERS classification of fracture pattern.

\begin{tabular}{|lll|}
\hline Type of fracture & $\begin{array}{l}\text { Number of } \\
\text { patient }\end{array}$ & $\begin{array}{l}\text { Percentage } \\
(\%)\end{array}$ \\
\hline 2 part & 16 & 45 \\
\hline 3 part & 15 & 42 \\
\hline 4 part & 4 & 13 \\
\hline Total & 35 & \\
\hline
\end{tabular}

Fifteen patients (42\%) were injured due to fall on outstretched hand, sixteen $(46 \%)$ were injured in road traffic accidents one patient $(3 \%)$ had seizure episode and three $(9 \%)$ patients were injured due to fall from height.

Table 4: Distribution of age and mechanism of injury.

\begin{tabular}{|llll|}
\hline Mechanism of injury & $<\mathbf{5 0}$ yrs & $>\mathbf{5 0}$ yrs & Total \\
\hline $\begin{array}{l}\text { Fall on out stretched } \\
\text { hand }\end{array}$ & 03 & 12 & $15(42)$ \\
\hline Road traffic accident & 16 & $\mathrm{O}$ & $16(46)$ \\
\hline Seizures & 00 & 01 & $01(3)$ \\
\hline Fall from height & 03 & 00 & $03(9)$ \\
\hline Total & 22 & 13 & 35 \\
\hline
\end{tabular}

Out of the thirty five patients in our study, $22(62 \%)$ were less than 50 years and thirteen $(38 \%)$ were older than 50 years of age. Of the thirteen patients older than 50 years twelve patients $(92 \%)$ had sustained fractures due to fall on outstretched hand.

This shows that proximal humerus fractures are now increasingly seen in younger population with good bone stock following high energy trauma and in elderly it is essentially encountered following a low energy trauma.

All our patients followed up till complete range of motion was achieved. The average follow up was of 11 months with maximum follow up being one year. We lost one patient to follow up owing to mortality caused by a sudden myocardial infarction unrelated to the fracture suffered in the sixth week of recovery hence she was excluded from the study. Thus a total of 34 patients completed their follow up and were evaluated as a part of our study.

All fractures united with average time taken for union was approximately 3 months. Union was based on clinical and radiological findings as earlier mentioned.

Patients were assessed for their range of motion at the end of every follow up and all their shoulder range of motion was evaluated. Abduction and external rotation were given prime importance and consideration since they constituted the bulk of the damage sustained muscles. Mean forward flexion was $123^{\circ}$, abduction $124^{\circ}$, external rotation was $30^{\circ}$ and mean internal rotation was $53^{\circ}$ at the final follow up.
Table 5: Range of motion.

\begin{tabular}{|c|c|c|c|c|}
\hline Parameter & $\begin{array}{l}6 \\
\text { week }\end{array}$ & $\begin{array}{l}12 \\
\text { week }\end{array}$ & $\begin{array}{l}24 \\
\text { week }\end{array}$ & $\begin{array}{l}48 \\
\text { week }\end{array}$ \\
\hline Forward flexion & 54 & 83 & 121 & 122 \\
\hline Abduction & 54 & 78 & 119 & 124 \\
\hline Extension & 15 & 24 & 30 & 30 \\
\hline Internal rotation & 24 & 34 & 53 & 50 \\
\hline
\end{tabular}

Average SPADI score for different fracture type according to NEERS classification are given in Table 6, suggesting that there is no statistically significant difference between these fractures types managed with locking plate.

On comparison of above with respect to age distribution, patients in 6th decade show comparatively low functional outcome after surgery as compare to lower age group.

The SPADI score which was used was assessed using unpaired and paired $\mathrm{T}$ test and the confidence interval was used was $99 \%$. It was observed that the score at 6 weeks significantly improved at 12 weeks with a $p$ value of <0.01. Similar statistically significant improvement was seen in the scores between 12 weeks and 6 months with the $\mathrm{p}$ value being $<0.01$.

Finally, the SPADI score at the final follow up was assessed and compared to the previous follow up and the immediate postoperative scores and it was noticed that the score was significant with $\mathrm{p}<0.01$.

It was observed that the SPADI score when compared statistically was not significantly different i.e. $\mathrm{p}>0.05$ for the $95 \%$ CI between the final follow up for 2 part, 3 part or 4 part fractures.

It was observed that with physiotherapy under supervision only initially, these patients greatly improved with the scores from 6 weeks to one year. At each progressive follow-up SPADI score decreased, suggesting that lesser the score better the functional outcome. Overall functional outcome found to be moderate to good in $92 \%$ of patients but $8 \%$ patients had poor outcome due to associated complications postoperatively.

Radiological evaluation was done by measuring the HSA. The average postoperative HSA was $134.1 \pm 4.4$ degrees (range 116- 140 degrees. On follow up $x$ rays, the average HSA after union was $132.5 \pm 1.2$ degrees. The mean union time was $6.3 \pm 3$ months (range 4 to 7 months). No relationship was found between the functional outcomes (as measured by SPADI score) and the HSA $(p=0.67)$. However, the cases with varus deformity that is, HSA less than 130 degrees had lower SPADI scores than those with HSA more than 130 degrees although there was no significant statistical difference between the two groups $(\mathrm{p}=0.85)$. 
Table 6: Mean SPADI score and ROM according to fracture pattern.

\begin{tabular}{|lllllll|}
\hline $\begin{array}{l}\text { Type of } \\
\text { fracture }\end{array}$ & $\begin{array}{l}\mathbf{6} \text { months } \\
\text { follow up }\end{array}$ & $\begin{array}{l}\mathbf{1 2} \text { months } \\
\text { follow-up }\end{array}$ & $\begin{array}{l}\text { Forward } \\
\text { flexion }\end{array}$ & Abduction & $\begin{array}{l}\text { External } \\
\text { rotation }\end{array}$ & $\begin{array}{l}\text { Internal } \\
\text { rotation }\end{array}$ \\
\hline 2 part & 23.38 & 10.22 & 123 & 125 & 32 & 55 \\
\hline 3 part & 24.21 & 10.38 & 124 & 121 & 30 & 53 \\
\hline 4 part & 24.57 & 10.20 & 118 & 120 & 24 & 50 \\
\hline
\end{tabular}

Table 7: Mean SPADI score and ROM according to age distribution.

\begin{tabular}{|lllllll|}
\hline $\begin{array}{l}\text { Age } \\
\text { distribution }\end{array}$ & $\begin{array}{l}\text { 6 months } \\
\text { follow-up }\end{array}$ & $\begin{array}{l}\text { 12 months } \\
\text { follow up }\end{array}$ & $\begin{array}{l}\text { Forward } \\
\text { flexion }\end{array}$ & Abduction & $\begin{array}{l}\text { External } \\
\text { rotation }\end{array}$ & $\begin{array}{l}\text { Internal } \\
\text { rotation }\end{array}$ \\
\hline $\mathbf{2 1 - 3 0}$ yrs & 22.01 & 7.1 & 127 & 127 & 30 & 56 \\
\hline $\mathbf{3 1 - 4 0}$ yrs & 19.67 & 7.6 & 129 & 132 & 32 & 56 \\
\hline $\mathbf{4 1 - 5 0}$ yrs & 22.07 & 8.6 & 127 & 130 & 31 & 56 \\
\hline $\mathbf{5 1 - 6 0}$ yrs & 27.80 & 14.72 & 115 & 113 & 26 & 50 \\
\hline
\end{tabular}
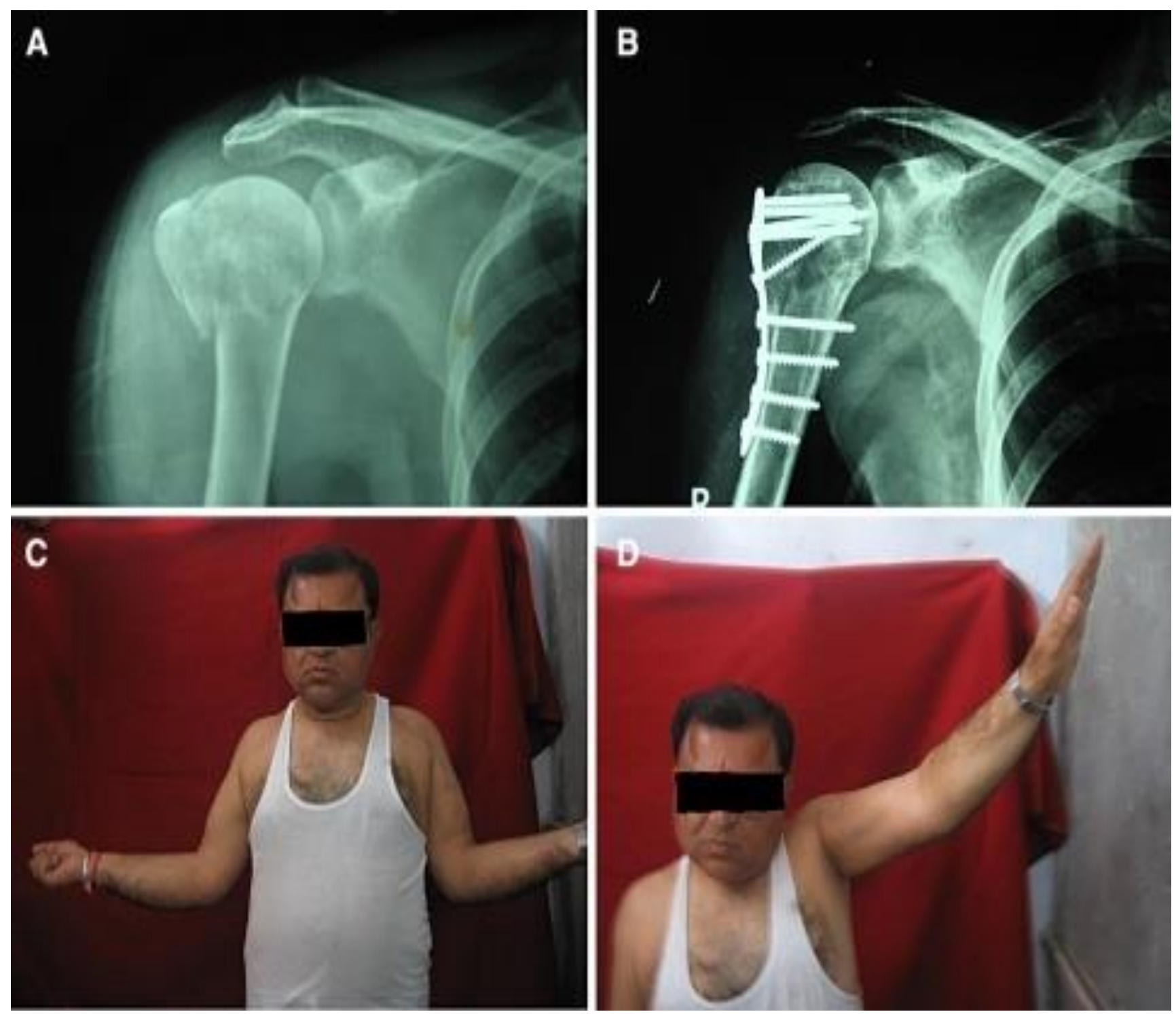

Figure 3: 59 year old male with $A=4$ part proximal humerus fracture, $B=P$ ostoperative $X$-ray after fixation with locking plate and suturing the tuberosities with non-absorbable sutures, $\mathrm{C}$ and $\mathrm{D}=\mathrm{ROM}$ at 6 months follow up. 


\section{DISCUSSION}

Although proximal humerus fracture may occur in any age group an increased frequency occurs in the elderly individuals because of the age-related increase in osteoporosis.

In our study we found $35 \%$ of fractures are occurred in older age group and out of 5 female patients, in 4 patients it occurred after menopause. In our study $65 \%$ patients are from age group of less than 50 years of which $72 \%$ patients had history of heavy trauma. Road traffic accident, fall from height are commonest cause of injury in young population of our study these results are matching with study of Muthuuri and colleague. ${ }^{1}$

Our study showed a substantial pre-ponderence to male patients indicating that the fracture was sustained more by high energy traffic accidents by that part of the population being represent by ratio of $6: 1$.

Singer and colleagues also showed that the greatest number of fractures in adult men appeared during the active ages, whereas women a dramatic increase was noted after menopause. ${ }^{9}$ As age group of our study 20 to $60 \mathrm{yrs}$ and as this fracture in female common after menopause and out of 5 females 4 are from 5 th and 6 th decade.

The recent evolution of locking plate technology for proximal humerus fractures seems to have revolutionized the management of these fractures.

However there have been very limited prospective studies investigating the results of locking plates for open reduction and internal fixation of proximal humeral fractures. ${ }^{11-16}$

Most of these studies have reported good functional outcomes and recommended the use of locking plates for proximal humerus fractures especially in elderly patients with poor bone quality.

In a recent biomechanical study demonstrated significantly greater torsional stiffness and similar bending stability to blade plates therefore indicating potential advantages for the locking plate. ${ }^{27}$

In our study fracture pattern was compared for the statistical significance of SPADI score it was observed that 2 part fracture, 3 part fracture did as well as 4 part fracture clinically, which was confirmed by absence of statistical significance.

This indicates our procedure worked uniformly over all 2 part, 3 part and 4 part fractures of proximal humerus compared to varied results seen in different modes of treatment. $5,18,19,21,22$
The results of our study shows good outcome in approximately $92 \%$ of our patients.

Early results of using locking plates in the management of displaced proximal humerus fractures have shown that this technology compares quite favourably with hemiarthroplasty and older fixation techniques.

In our study, patients treated with locking plates had mean forward flexion of $123^{\circ}$, abduction of $124^{\circ}$, mean external rotation of $30^{\circ}$ and internal rotation $53^{\circ}$ at 1 year follow-up. With maximum improvement in range of movement occurred between interval of 12 weeks to 24 weeks due to complete fracture union occurred approximately up to 12 weeks.

In a study of patients with hemiarthroplasties and longterm follow-up Antuna and colleagues found mean forward elevation of only $100^{\circ}$ and mean external rotation of $30^{\circ} .^{18}$

Dietrich and colleagues compared locking plate osteosynthesis with hemiarthroplasty and reported significantly better functional outcomes with locking plate fixation. ${ }^{19}$

Similarly Solberg and colleagues studied 3- and 4- part fractures managed with either fixed- angle plates or hemiarthroplasty and found that open repair with locking plates had better patient outcomes especially with 3-part fractures though the complication rate was higher. ${ }^{20}$

Outcomes of locking plates are comparable to those of alternative fixation techniques.

Handschin and colleagues compared one-third tubular plates bent in a fixed angle and proximal humerus locking plate implants and found no significant difference in complication rates or functional outcomes. ${ }^{21}$

They also observed that locking plates may be advantageous only in certain settings, such as osteoporotic bone.

In another study, which compared plate osteosynthesis using angular stable screws and intramedullary nailing there was no statistical difference in functional outcomes between the groups at 1-year follow-up. ${ }^{22}$

Due to complications $8 \%$ patients had poor outcome secondary to restricted range of motion.

In our study we found equal mean SPADI score in all patients irrespective of their fracture type.

We found no significant difference in the functional outcome using SPADI SCORE, after proximal humerus locking plate fixation between fracture types using NEERS classification system, for a minimum follow up of 12 months postoperatively. 
On comparing the functional outcome and SPADI score on the basis of age distribution we found low outcome in patients with $6^{\text {th }}$ decade as compared to lower age group but our results are better than old methods used for fixation. ${ }^{23-26}$

In this study, no significant difference was noted between the HSA and SPADI score. Similar result was found in a study conducted by Gonc et al, in which they found no association with the mean postoperative HSA and functional outcome measured by the Constant and Murley score. $^{27}$

Funding: No funding sources

Conflict of interest: None declared

Ethical approval: The study was approved by the institutional ethics committee

\section{REFERENCES}

1. Muthuuri JM. Outcome Of Plate Osteosynthesis In The Management Of Proximal Humeral Fractures In Adults. 8th ed. US: CBSPD; 2008.

2. Karataglis D, Stavridis SI, Petsatodis G. New trends in fixation of proximal humeral fractures: a review. Injury. 2011;42(4):330-8.

3. Gradl G, Knobe M, Pape HC. Decision making in displaced fractures of the proximal humerus: fracture or surgeon based? Int Orthop. 2015;39(2):329-34.

4. Charles Neer II. Displaced proximal humeral fractures. I. Classification and evaluation. J Bone Joint Surg Am. 1970;52:1077-89.

5. Siffri PC, Peindl RD, Coley ER, Norton J, Connor PM, Kellam JF. Biomechanical Analysis of Blade Plate Versus Locking Plate Fixation for a Proximal Humerus Fracture: Comparison Using Cadaveric and Synthetic Humeri. J Orthop Trauma. 2006;20:547-54.

6. Gardner MJ, Griffith MH, Dines JS. The extended anterolateral acromial approach allows minimally invasive access to the proximal humerus. Clin Orthop Relat Res. 2005;434:123-9.

7. Rouch KE, Budiman-Muk E, Songsiridej N, Lertratanakul Y. Development of a Shoulder Pain and Disability Index Arthritis Care Res. 1991;4:143-9.

8. Hertel R, Knothe U, Ballmer FT. Geometry of the proximal humerus and implications for prosthetic design. J Shoulder Elbow Surg. 2002;11(4):331-8.

9. Singer BR, McLauchlan GJ, Robinson CM, Christi J. Epidemiology of fractures in 15000 adults The influence of age and gender. J Bone Joint Surg [Br]. 1998;80:243.

10. Südkamp N, Bayer J, Hepp P. Open reduction and internal fixation of proximal humeral fractures with use of the locking proximal humerus plate. Results of a prospective, multicenter, observational study. J Bone Joint Surg Am. 2009;91(6):1320-8.
11. Fankhauser F, Boldin C, Schippinger G, Haunschmid C, Szyszkowitz R. A new locking plate for unstable fractures of the proximal humerus. Clin Orthop Relat Res. 2005;(430):176-81.

12. Koukakis A, Apostolou CD, Taneja T, Korres DS, Amini A. Fixation of proximal humerus fractures using the PHILOS plate: early experience. Clin. Orthop. Relat Res. 2006;442:115-20.

13. Kettler M, Biberthaler P, Braunstein V, Zeiler C, Kroetz M, Mutschler W. Treatment of proximal humeral fractures with the PHILOS angular stable plate. Presentation of 225 cases of dislocated fractures. Unfallchirurg. 2006;109(12):1032-40.

14. Bigorre $\mathrm{N}$, Talha A, Cronier $\mathrm{P}$, Hubert L, Toulemonde JL, Massin P. A prospective study of a new locking plate for proximal humeral fracture. Injury. 2009;40(2):192-6.

15. Geiger EV. Functional outcome and complications following proximal humerus interlocking system plate fixation in proximal humerus fracture. Acta orthopaedic traumatol turc. 2010;44(1):1-6.

16. Spross C, Platz A, Rufibach K, Lattmann T, Forberger J, Dietrich M. The PHILOS plate for proximal humeral fractures--risk factors for complications at one year. J Trauma Acute Care Surg. 2012;72(3):783-9.

17. Ong CC, Kwon YW, Walsh M, Davidovitch R, Zuckermann JD, Egol KA. Outcomes of Open Reduction and Internal Fixation of Proximal Humerus Fractures Managed With Locking Plates. Am J Orthop. 2012;41(9):407-12.

18. Antuña SA, Sperling JW, Cofield RH. Shoulder hemiarthroplasty for acute fractures of the proximal humerus: a minimum five-year follow-up. J Shoulder Elbow Surg. 2008;17(2):202-9.

19. Dietrich M, Meier C, Lattmann T, Zingg U, Grüninger P, Platz A. Complex fracture of the proximal humerus in the elderly. Locking plate osteosynthesis vs hemiarthroplasty. Chirurg. 2008;79(3):231-40.

20. Solberg BD, Moon CN, Franco DP, Paiement GD. Surgical treatment of three and four-part proximal humeral fractures. J Bone Joint Surg Am. 2009;91(7):1689-97.

21. Handschin AE, Cardell M, Contaldo C, Trentz O, Wanner GA. Functional results of angular-stable plate fixation in displaced proximal humeral fractures. Injury. 2008;39(3):306-13.

22. Use of angle-stable implants for proximal humeral fractures: prospective study. J Bone Joint Surg Br. 2004;86(6):848-55.

23. Wijgman AJ, Roolker W, Patt TW. Open reduction and internal fixation of three and four-part fractures of the proximal part of the humerus. J Bone Joint Surg Am. 2002;84(11):1919-25.

24. Esser RD. Open reduction and internal fixation of three- and four-part fractures of the proximal humerus. Clin Orthop Relat Res. 1994;(299):24451. 
25. Paavolainen P, Björkenheim JM, Slätis P, Paukku P. Operative treatment of severe proximal humeral fractures. Acta Orthop Scand. 1983;54(3):374-9.

26. Aggarwal S, Bali K, Dhillon MS, Kumar V, Mootha AK. Displaced proximal humeral fractures: an Indian experience with locking plates. J Orthop Surg Res. 2010;5:60.

27. Ugur Gonç, Mesut Atabek, Kürs, at Teker, Altug Tanriover. Minimally invasive plate osteosynthesis with PHILOS plate for proximal humerus fractures.
Acta Orthopaedica et Traumatologica Turcica. 2017;51:17-22.

Cite this article as: Mahajan NP, Palange ND, Pawar ED, Mangukiya HJ, Ramteke US, Ravesh V, et al. Radiological correlation with functional outcome in displaced proximal humerus fractures treated with locking plates: a prospective study of 35 cases. Int J Res Orthop 2018;4:471-9. 